\title{
Protective effect of cimetidine in carbon tetrachloride-treated rats.
}

\author{
Laurentiu Nedelcu $^{1 *}$, Vlaicu Șandor ${ }^{2}$, Dan L Dumitrașcu ${ }^{3}$ \\ ${ }^{1}$ Department of Internal Medicine, Transilvania University, Brasov, Romania \\ ${ }^{2}$ Department of Pharmacology, Iuliu Hatieganu University of Medicine and Pharmacy, Cluj-Napoca, Romania \\ ${ }^{3}$ Department of Internal Medicine, Iuliu Hatieganu University of Medicine and Pharmacy, Cluj-Napoca, Romania
}

\begin{abstract}
Cimetidine may have hepatoprotective effects. We looked for the impact of cimetidine on the hepatic changes induced by carbon tetrachloride. Male Wistar-Bratislava albino rats were randomized into four groups. Group I, control (C) received physiologic saline solution (PSS) for 3 days. Group II (CT) received PSS but the last administration being followed by a carbon tetrachloride (CT) subcutaneous (sc) injection. Group III (CT+CM) received Cimetidine (CM); at the last dose of CM there was an injection of CT as for group II. Group IV was treated only with CM. The rats were weighted at the beginning of the treatment and at the moment of the euthanasia. Blood sampled were collected. The organs were removed and weighted. A sample of left lobe of the liver was taken for histological analysis. We have analysed morphometric characteristics of the organs, histological and biochemical changes. The acute hepatotoxicity effect of $\mathbf{C C l}_{4}$ in rats after a single dose was demonstrated after $\mathbf{2 4}$ hours. $\mathbf{C C l}_{4}$ (group II) increases the relative weight of the liver and histologically induces fatty dystrophy and extended centrilobular necrosis. The increase of ASAT and ALAT were massive. The preventive administered cimetidine, associated with $\mathrm{CCl}_{4}$ (group III) has partially hepatic protection. The fatty infiltration is not present and the focal centrilobular necrosis is less extended. The effect of hepatic cytolysis enzymes is remarkable. Acute administering at rats, $\mathrm{CCL}_{\mathbf{4}}$ has a characteristic hepatotoxicity spectrum, induces fatty dystrophy, hepatic centrilobular necrosis and massive increases of transaminases. Cimetidine in subacute treatment, preventive, for 3 days has protective action relative to $\mathrm{CCl}_{4}$.
\end{abstract}

Keywords: Protective effect, Hepatotoxicity, Cimetidine, Carbon tetrachloride.

Accepted on February 13, 2019

\section{Introduction}

Carbon tetrachloride (CT) is frequently used in experimental models for acute hepatitis and hepatic cirrhosis [1,2]. The complexity of the acting mechanism makes the interpretation of the observed effects difficult but permits the exploration of different theories on the pathogenicity of toxic and other kinds of hepatitis [3]. In the same time, the study of the hepatic changes induced by $\mathrm{CT}$ under the influence of some medicines and chemical substances makes contributions to the experimental therapy of hepatitis [4]. Among the medications with possible impact on the evolution, cimetidine (CM) can favorably intervene through multiple effects in $\mathrm{CT}$ induced toxic hepatitis [5].

\section{Materials and Methods}

\section{Biologic material}

We have worked with male Wistar-Bratislava albino, body weight between 100-165 g, with standard feeding, with water ad libitum. The room temperature was between $18-20^{\circ} \mathrm{C}$, with natural light-darkness cycle.

\section{Experimental protocol}

Four groups of 8 animals were constituted through randomization.

Group I, control (C) received PSS, $2 \mathrm{ml} / \mathrm{kg}$ ip at 12 hours intervals, for 3 days. At the last ip injection with PSS there was also a sc injection of $0.25 \mathrm{ml}$ for each rat.

Group II (CT) received PSS as the first group, the last administration being followed by a $2.5 \mathrm{ml} / \mathrm{kg}$ CT sc injection.

Group III (CT+CM) received CM $25 \mu \mathrm{mol} / \mathrm{kg}$ at 12 hours (6 doses in total). At the last dose of $\mathrm{CM}$, there was an injection of CT as for group II.

Group IV is the group treated only with CM in doses and time intervals identical with the group III. 
The dose of $25 \mu \mathrm{moli} / \mathrm{kg}$ match to $6.31 \mathrm{mg} / \mathrm{kg}$ cimetidine. The six doses, separated at intervals of 12 hours, sum $37.86 \mathrm{mg} / \mathrm{kg}$ cimetidine.

This dose was chosen on the basis of previous attempts, proving effective on hepatic hypertrophy and necrosis and on the growth of cytolytic enzymes in acute intoxication with $\mathrm{CCl}_{4}$ in rats. The dose of cimetidine administered in rats in the present paper is close to or lower compared to the doses mentioned in other researchers [6].

The rats were weighted at the beginning of the treatment and at the moment of the euthanasia. The food was suspended at the moment of the CT administration and the euthanasia was done after 24 hours from that point. Immediately after the euthanasia, blood was sampled from the retro-orbital sinus for biochemical analysis of serum after coagulation and centrifugation. The transaminases were determined on a Beckman automatic analyser, in miliunits/ $1 \mathrm{ml}$.

Afterwards, the following organs were removed and weighted: liver, kidneys, heart, stomach, spleen and testicles. A sample of left lobe of the liver was taken for histological analysis. All the organs were put in the oven at $110^{\circ} \mathrm{C}$, for 24 hours, afterwards being again weighted. Herewith the total weight, the dry weight and by difference the water content of each organ was determined. The dry weight of the liver was corrected for the excised segment. For each type of weight the organ index (relative weight) was calculated by the ratio between the values of the organ weight in $\mathrm{mg}$ and $100 \mathrm{~g}$ of body weight units (100 $\mathrm{mg}$ tissue/100 g body weight).

The sample liver fragment was included in 10\% formaldehyde, fixed and sectioned at 7 microns. Hematoxylin eosin and Sudan III stains were used. The assessment of the pieces was done by a pathologists blinded on the therapy.

\section{Drugs used}

\section{Physiologic saline solution}

2. CT (carbon tetrachloride- $\mathrm{CCl}_{4}$ ) diluted in oleum Helianthi $1: 1$, administration of $2.5 \mathrm{ml} \mathrm{CCl}_{4}$, in a total volume of 5 $\mathrm{ml} / \mathrm{kg}, \mathrm{sc}$.

3. Cimetidine, aqueous solution $25 \mu \mathrm{mol} / \mathrm{kg}$ ip $(6.31 \mathrm{mg} / \mathrm{kg})$, calculated as base. The concentrated solution was diluted at the moment of administration.

\section{Statistical analysis}

Parametric tests (t-Student unpaired) were used for the relative weight of organs and the transaminases. The percentage analysis of the histological changes (fatty dystrophy and liver necrosis) was evaluated in $2 \times 2$ contingency tables. For both test types, the null hypothesis was rejected at $\mathrm{p}<0.05$ values.

\section{Ethics}

This study was approved by the local ethical committee and conducted according to the Declaration of Helsinki on Human and Animal Studies.

\section{Results}

The animals treated for 3 days with cimetidine and physiologic serum had a constant, unmodified behavior. After administering $\mathrm{CCl}_{4}$ an apparent reduction of motility can be observed in the rats of these groups. There are no observed differences on body weight between groups at the time of the euthanasia.

\section{Morphometric characteristics of the organs}

The liver is the organ with evident morphometric changes after administering $\mathrm{CCl}_{4}$ (Figure 1).

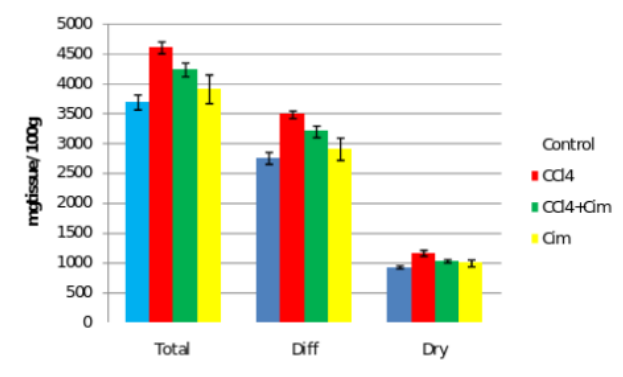

Figure 1. Liver relative weight.

$\mathrm{CCl}_{4}$ significantly increases the relative weight: total, dry and the water content of the organ. Cimetidine does not modify the morphometric hepatic parameters but associated with $\mathrm{CCl}_{4}$ significantly decreases it effect on relative weight, without getting close to the control group values. Regarding the dry residuum percentage there are no differences between the four groups.

At the kidney level there is a decrease of relative weight after cimetidine treatment and some variations of the dry residuum percentage (Figure 2).

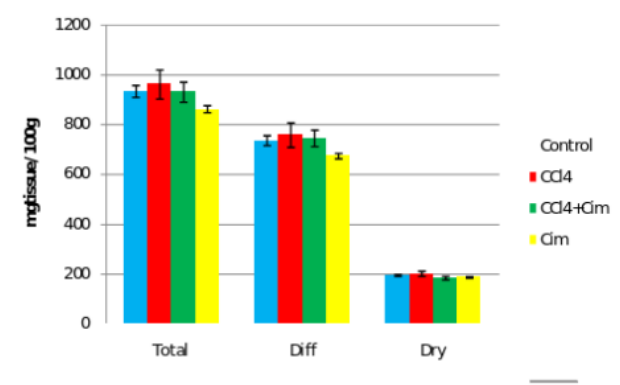

Figure 2. Kidney relative weight.

Regarding the spleen, the changes are evident only the combination $\mathrm{CCl}_{4}$ with $\mathrm{CM}$ (III) treated group with decrease of relative weight indexes. There are no significant differences of relative weight of the heart, stomach and testicles.

\section{Histological changes}

At the control group the hepatic architecture is preserved. Group IV, treated with cimetidine, presents on the majority of sections normal aspects, with preservation of the lobular 
structure. On one of the samples dilated sinusoids can be observed and on another two sections there are pronounced dystrophic changes and rare unicellular necrosis on another section (Figures 3 and 4).

The histologic aspect of the group II, treated with $\mathrm{CCl}_{4}$ is homogenous. On Sudan III stains, the fatty dystrophy is present at all the animals. The centrilobular necrosis, more or less extended is constantly observed. Group III, that has received besides $\mathrm{CCl}$, cimetidine, develops fatty dystrophy, most of the times macrovesicular fatty dystrophy. The centrilobular necrosis or necrobiosis is present at only 3 of the 7 animals of the group, pointing to a partial protection via cimetidine.

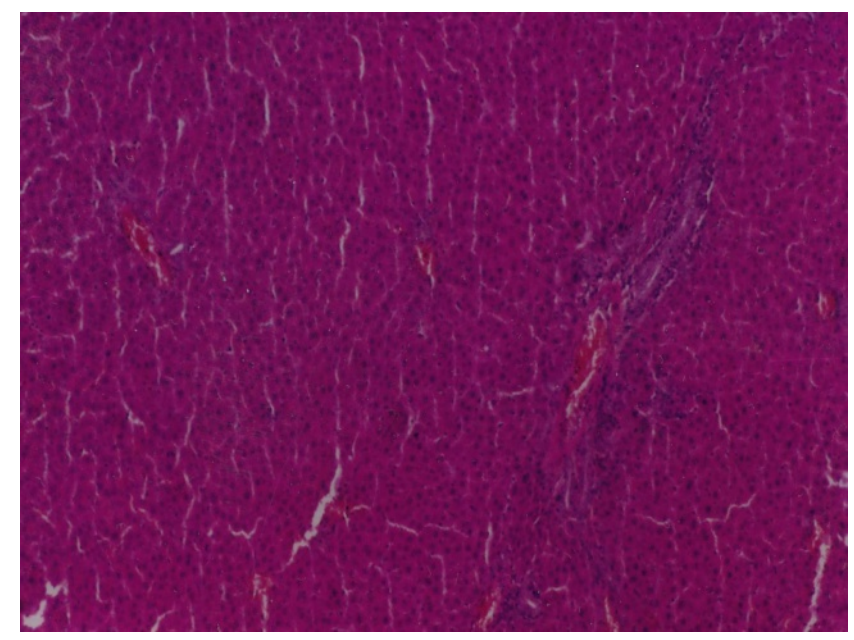

Figure 3. Haematoxylin-eosin staining. Control group (left) and group treated with cimetidine (right).

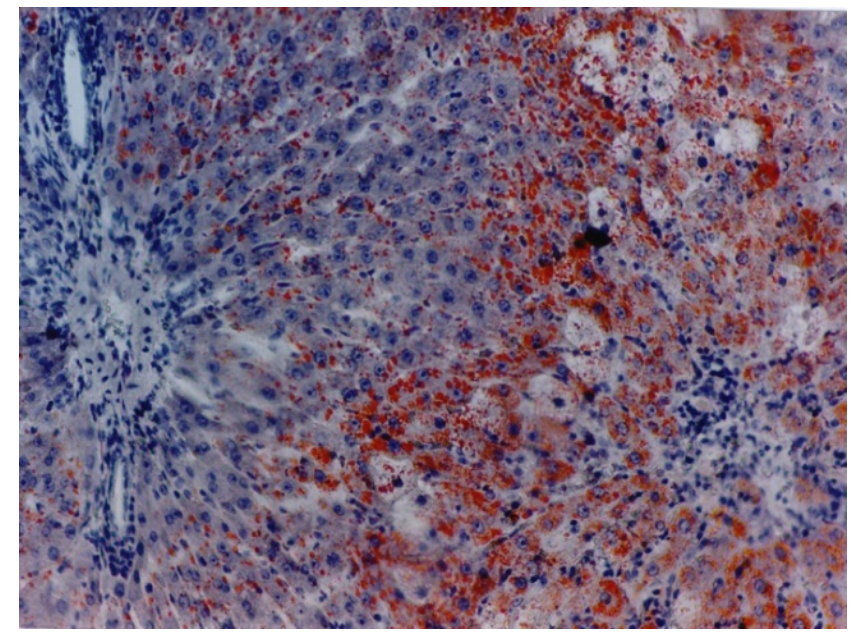

Figure 4. Sudan III staining. Carbon tetrachloride group (left) and group treated with carbon tetrachloride and cimetidine (right).

\section{Biochemical changes}

The serum transaminases initial values are relatively high (mostly ASAT), probably as a result of the minimal tissue lesions due to injections (Figure 5). $\mathrm{CCl}_{4}$ increases over 4 times the serum values of ASAT and almost 7 times the values of ALAT. Cimetidine significantly and substantially decreases the values of both transaminases, even if the values of the control group are not reached. An interesting aspect is observed at the cimetidine treated group, with decrease of the serum transaminases values (statistically significant for ASAT).

\section{Discussion}

The acute hepatotoxicity effect of $\mathrm{CCl}_{4}$ in rats after a single dose was demonstrated after 24 hours. $\mathrm{CCl}_{4}$ (group II) increases the relative weight of the liver (all three aspects) (Figure 1), and histologically induces fatty dystrophy and extended centrilobular necrosis at all the animals that received it. The increase of ASAT and ALAT is massive (Figure 5).

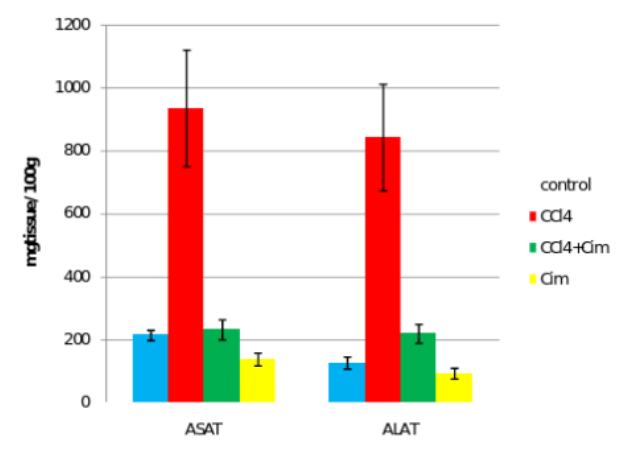

Figure 5. Seric transaminases.

$\mathrm{CCl}_{4}$ does not have notable morphometric effects on other organs.

Cimetidine (group IV) has insignificant effects of morphometric parameters with the exception of a slight decrease of renal relative weight In 2 animals, after cimetidine, fatty dystrophy areas and in one animal rare cellular necrosis have appeared.

The preventive administered cimetidine; associated with $\mathrm{CCl}_{4}$ (group III) has partially hepatic protection. Cimetidine diminishes the CT augmented hepatic relative weight that remains however above the control group. As for histology, the fatty infiltration is not present but the focal centrilobular necrosis is less extended. The effect of hepatic cytolysis enzymes is remarkable, when cimetidine is associated with CC14. ASAT has values similar with the control group and ALAT has a consistent decrease.

\section{$\mathrm{CCl}_{4}$ toxicity mechanisms}

Numerous metabolites after $\mathrm{CCl}_{4}$ administering have been observed in animals [7].

The metabolic activation of $\mathrm{CCl}_{4}$, through intermediate reactive compounds starts and maintains a cascade cell reaction that overcomes the homeostatic capacity of the involved systems [8]. The evaluation of the role of each component and the protective therapeutic intervention is made difficult by the multitude of involved factors in the pathologic process. 


\section{Action pathways of $\mathrm{H} 2$ antihistamines in $\mathrm{CCl}_{4}$ induced acute hepatopathy}

A protector profile of cimetidine [9] can be seen (partially, inconstant and that cannot be reproduced). As for the other $\mathrm{H} 2$ antihistamines, the heterogeneity of the effects and the inconsistence or the absence of hepatic protection makes a class effect less likely.

Cimetidine is a microsomal mixed oxidase inhibitor with effects on CYP2E1, CYP3A and CYP1A. Ranitidine has much smaller effect and famotidine does not interact with the $\mathrm{CYP}_{450}$ system. On isolated rat hepatocytes, $\mathrm{CCl}_{4}$ has a higher centrilobular cytotoxic activity and cimetidine decreases the hepatic lesions in this area. Specific inhibitors of CYP2E1 have a higher protection than cimetidine [10].

In vivo, the increase of serum transaminases after $\mathrm{CCl}_{4}$ is significantly lowered by cimetidine, ranitidine and famotidine. Only cimetidine decreases lipid peroxides. The common protective intervention pathway of the three drugs, linked or not by the antihistaminic $\mathrm{H} 2$ effect could be placed in the antioxidative defense area. The $\mathrm{H} 2$ receptors are situated in competent cells, neutrophiles [11] and monocites [12]. Cimetidine and ranitidine are inhibiting the generation of superoxyde in active leucocytes. The creation of superoxyde $\left(\mathrm{O}^{2-}\right)$ and $\mathrm{H}_{2} \mathrm{O}_{2}$ by human neutrophiles is dose-dependent inhibited by cimetidine and famotidine but is not influenced by ranitidine [13].

The activation of free radical-scavenging $\mathrm{H} 2$ blockers is highlighted on in vivo specific tests. They have a scavenging effect on nitric oxide (more expressed at famotidine), on $\mathrm{H}_{2} \mathrm{O}_{2}$ (cimetidine and ranitidine) and DPPH (1,1-diphenyl-2 picryl hydrazyl). They are inactive on potassium ferricyanide tests [8]. This data shows that $\mathrm{H} 2$ antihistamines have favorable effects of oxidative stress.

The antitoxic effects of cimetidine and in lesser extent of other $\mathrm{H} 2$ antihistamines have been observed in experimental conditions on other drugs. Cimetidine has hepatoprotective effects in halothane, other halogenated hydrocarbons overdose and paracetamol acute intoxication. Cimetidine blocks the toxic activation of dapsonen [14], effect with clinical benefits, reducing the methemoglobinemia in patients treated with this drug.

\section{Sporadic hepatic dystrophic changes induced by cimetidine}

In the exposed experimental conditions, moderate dystrophic lesions induced by cimetidine are evident in a few animals. In past research in our laboratory on similar rats, cimetidine has not induced histological lesions.

Cimetidine and other $\mathrm{H} 2$ antihistamines have extensive clinical uses, rare hepatic adverse reactions and the determining factors for adverse reactions are hard to predict.

Out of the main three $\mathrm{H} 2$ antihistamines, cimetidine has the most frequent hepatotoxic effects even after a short period of treatment [15], compared with ranitidine and with famotidine [16,17]. A possible subacute liver failure has been reported after nizatidine. Clinically apparent liver injury of cimetidine and ranitidine has been appreciated at 1:20000 to $1: 100000$ users.

$\mathrm{H} 2$ antihistamines induced hepatitis evolves acute in most cases, with transaminases, alkaline phosphatase and total bilirubin increases as hepatocellular or cholestatic type. The biopsies have highlighted bridging hepatic necrosis, centrilobular necrosis and intrahepatic or canalicular cholestasis.. The severity of the manifestations is variable. The interruption of drug administration leads to gradual vanishing of adverse reactions. Reintroducing the $\mathrm{H} 2$ antihistamine induces in a short time the onset of the symptoms suggesting the immunologic nature of the drug induced hepatitis. At $\mathrm{H} 2$ antihistamines administered rarely or in episodes, the hepatotoxic reactions have been observed at niperotidine, ebrotidine [18] and zaltidine. Oxmetidine, as much as it was used, has been incriminated as the most frequent inducer of adverse reactions in humans. Also on rat hepatocyte cultures, oxmetidine releases high concentrations of ASAT, effect absent at cimetidine and ranitidine. On rat hepatocytes, cimetidine, ranitidine and famotidine do not influence the DNA replication in the presence or absence of insulin and epidermal growth factor (EGF). At submaximum doses, cimetidine stimulates the DNA biosynthesis along with the two growth factors.. At high concentrations, cimetidine induces DNA fragmentation.

The effects of $\mathrm{H} 2$ antihistamines on hepatic regeneration are contradictory. In some instances, cimetidine and ranitidine do not modify the hepatic regeneration indices in rats [19] or even are stimulating the DNA biosynthesis and cell proliferation Conversely, also in rats, cimetidine and ranitidine are inhibiting the cell regeneration after partial hepatectomy, effect absent for famotidine [20]. In a more complex experimental scheme, in the rat hepatic cell culture a serum from partial hepatectomy individuals and treated with $\mathrm{H} 2$ antihistamines was introduced. The hepatocyte proliferation inhibition was expressed at the cimetidine treatment serum.

At sub-cellular level, cimetidine diminished the oxidative phosphorylation in rat liver and brain mitochondria [21].

Returning to the inconsistency of the hepatic detrimental effects, observed by us as inconstant after cimetidine, it turns out as the same heterogenic aspect and even contrary to biographic data on this subject.

\section{Conclusion}

Acute administration of $2.5 \mathrm{ml} / \mathrm{kg} \mathrm{sc}$, in rats, $\mathrm{CCL}_{4}$ has a characteristic hepatotoxicity, constantly inducing fatty dystrophy and hepatic centrilobular necrosis. At $24 \mathrm{~h}$ after $\mathrm{CCl}_{4}$ administration, serum ASAT and ALAT have massive increases. $\mathrm{CCl} 4$ increases the relative, total, dry weight and the water content of the liver, without similar effects on other organs. 
Cimetidine in subacute administration, for 3 days $(6 \times 25$ $\mu \mathrm{mol} / \mathrm{kg}$ ip) has protective action relative to $\mathrm{CCl}_{4}$. It decreases the hepatic relative weight, decreases the number of animals with centrilobular necrosis but is not influencing hepatic fatty dystrophy. Cimetidine reduces the serum transaminases increase determined by $\mathrm{CCl}_{4}$.

The protection awarded by cimetidine is taking place probably by blocking the formation and action of $\mathrm{CCl}_{4}$ reactive metabolites.

\section{References}

1. Weber LW, Boll M, Stampfl A. Hepatotoxicity and mechanism of action of haloalkanes: carbon tetrachloride as a toxicological model. Crit Rev Toxicol 2003; 33: 105-136.

2. Weiler-Normann C, Herkel J, Lohse AW. Mouse models of liver fibrosis. Gastroenterol 2007; 45: 43-50.

3. Manibusan MK, Odin M, Eastmond DA. Postulated carbon tetrachloride mode of action: a review. J Environ Sci Health C Environ Carcinog Ecotoxicol Rev 2007; 25: 185-209.

4. Jaeschke H, Williams CD, McGill MR, Xie Y, Ramachandran A. Models of drug-induced liver injury for evaluation of phytotherapeutics and other natural products. Food Chem Toxicol 2013; 55: 279-289.

5. Cluet JL, Boisset M, Boudene C. Effect of pretreatment with cimetidine or phenobarbital on lipoperoxidation in carbon tetrachloride- and trichloroethylene-dosed rats. Toxicology 1986; 38: 91-102.

6. Leonard TB, Dent JG. Effects of $\mathrm{H} 2$ receptor antagonists on the hepatotoxicity of various chemicals. Res Commun Chem Pathol Pharmacol 1984; 44: 375-388.

7. Reiner O, Uehleke H. Bildung von Tetrachlorkohlenstoff an reduziertes mikrosomales Cytochrom P-450 und an Häm. Hoppe Seylers Z Physiol Chem 1971; 352: 1048-1052.

8. Ingawale DK, Mandlik SK, Naik SR. Models of hepatotoxicity and the underlying cellular, biochemical and immunological mechanism(s): a critical discussion. Environ Toxicol Pharmacol 2014; 37: 118-133.

9. Ahmadi A, Ebrahimzadeh MA, Ahmad-Ashrafi S, Karami M, Mahdavi MR, Saravi SS. Hepatoprotective, antinociceptive and antioxidant activities of cimetidine, ranitidine and famotidine as histamine $\mathrm{H} 2$ receptor antagonists. Fundam Clin Pharmacol 2011; 25: 72-79.

10. Lindros KO, Cai YA, Penttila KE. Role of ethanolinducible cytochrome P-450 IIE1 in carbon tetrachloride- induced damage to centrilobular hepatocytes from ethanol-treated rats. Hepatology 1990; 12: 1092-1097.

11. Cíz M, Lojek A. Modulation of neutrophil oxidative burst via histamine receptors. Br J Pharmacol 2013; 170: 17-22.

12. Werner K, Neumann D, Seifert R. Analysis of the histamine H2-receptor in human monocytes. Biochem Pharmacol 2014; 92: 369-379.

13. Mikawa K, Akamatsu H, Nishina K . The effects of cimetidine, ranitidine, and famotidine on human neutrophil functions. Anesth Analg 1999; 89: 218-224.

14. Gill HJ, Tingle MD, Park BK. N-Hydroxylation of dapsone by multiple enzymes of cytochrome P450: implications for inhibition of haemotoxicity. $\mathrm{Br} \mathrm{J}$ Clin Pharmacol 1995; 40: 531-538.

15. Rudy E. Rare but important ADRs: Histamine H2receptor antagonist-induced nephrotoxicity and hepatotoxicity. Drug Therapy Topics 2001; 30: 23-25.

16. Gupta N, Patel C, Panda M. Hepatitis following famotidine: a case report. Cases J 2009; 2: 89.

17. Jimenez-Saenz M, Argüelles-Arias F, Herrerías-Gutiérrez JM, Durán-Quintana JA. Acute cholestatic hepatitis in a child treated with famotidine. Am J Gastroenterol 2000; 95: 3665-3666.

18. Castillo JR, Torelló J, Hernandez A. Liver injury caused by ebrotidine: a new example of the utility of the postmarketing surveillance. Eur J Clin Pharmacol 2000; 56: 187-189.

19. Lee SD, Wang JY, Cho CH. Effects of H2- receptor antagonists on the rat liver after partial hepatectomy or carbon tetrachloride-induced hepatic injury. Scand J Gastroenterol 1986; 21: 984-990.

20. Kanashima R, Kobayashi M. Famotidine does not inhibit liver regeneration. Eur Surg Res 1989; 21: 190-195.

21. Ghersi-Egea JF, Sautegeau A, Walther B, Minn A, Saunier C. Cimetidine inhibits cerebral and hepatic mitochondrial respiration in rat. Toxicol Lett 1986; 34: 253-259.

\section{*Correspondence to}

Laurentiu Nedelcu

Department of Internal Medicine

Transilvania University

Romania 